\title{
Investigation of Radial Swirler Effect on Flow Pattern inside a Gas Turbine Combustor
}

\author{
Yehia A. Eldrainy \\ Department of Aeronautical Engineering, Faculty of Mechanical Engineering \\ Universiti Teknologi Malaysia, 81310 Skudai, Johor Malaysia \\ Tel: 6-013-751-3221 E-mail: yeldrainy@yahoo.com \\ Mohd Fairuz bin Ahmad@Ibrahim \\ Department of Aeronautical Engineering, Faculty of Mechanical Engineering \\ Universiti Teknologi Malaysia, 81310 Skudai, Johor Malaysia \\ Tel: 6-013-719-0498 E-mail: mohdfairuz.ahmadibrahim@malakoff.com.my \\ Mohammad Nazri Mohd Jaafar (Corresponding author) \\ Department of Aeronautical Engineering, Faculty of Mechanical Engineering \\ Universiti Teknologi Malaysia, 81310 Skudai, Johor Malaysia \\ Tel: 6-07-553-4851Ｅ-mail: nazri@fkm.utm.my
}

\begin{abstract}
A study was conducted to investigate the flow pattern in a gas turbine combustor using numerical and experimental approaches. The main function of a combustor is to burn the air-fuel mixture then to admit the high energy burnt gases, with uniform and limited temperature, to drive the turbine blades. The gas temperature must not exceed a certain allowable temperature to prevent any damage of the blades. Flow pattern within the combustor has a great effect on the self sustaining flame, mixing of fuel and air, combustion intensity and combustor exit temperature uniformity. For this reason, a radial vaned swirler was used in this study to demonstrate its effect on the flow pattern within the combustor. The radial swirler vanes had an aerodynamically curved profile to allow the incoming axial flow to turn gradually and hence to inhibit the flow separation on the suction side of the vane. Therefore, smooth flow turning, higher tangential and radial-velocity components can be generated at the swirler exit with lower pressure loss. Three swirler vane angles $40^{\circ}, 50^{\circ}$ and $60^{\circ}$ corresponding to swirl numbers of $0.35,0.54$ and 1.13 were used to evaluate their effect on the combustor aerodynamics. The results show that the swirl number has a direct proportion relationship with the size and shape of the central recirculation zone as well as the corner recirculation. It is concluded that with the use of $40^{\circ}, 50^{\circ}$ and $60^{\circ}$ vane angles swirler, the vortex breakdown phenomena occurs at different intensities and sizes.
\end{abstract}

Keywords: Vane swirlers, Recirculation zone, Swirl number, Combustor flow pattern, CFD simulation

\section{Introduction}

The main focus of this research is to investigate the dynamics of the swirling flow in a can type gas turbine combustor. Aerodynamic curved vane radial swirlers with various vane angles were used. Flow pattern characteristics include velocity components and turbulent stresses, which are the main characteristics of the swirling flows, have been studied to understand the physical process both by experimental investigations and by numerical modeling CFD software Fluent 6.3 (Fluent user manual 2006).

In gas turbine combustor, it is necessary to maintain a stationary flame within a high velocity air stream. The flame propagates through the unburned mixture at a certain speed, accordingly the mixture have to be maintained within the same certain limits for flame stabilization. I.e. For flame travel in speed higher than mixture speed, the flame blowout occurs. In order to overcome this difficulty, a region of recirculation downstream the main burner or the bluff body should be established. This region creates areas of local low stream velocity equal to the flame speed which is used to hold the flame, hence to sustain the combustion.

Air swirlers are used as a flame holder by adding swirl to the incoming air. The presence of swirl results in setting up of radial and axial pressure gradients, which in turn influence the flow fields. In case of strong swirl the adverse axial 
pressure gradient is sufficiently large to result in reverse flow along the axis and generating an internal circulation zone (Lefebvre, 1983; Mellor, 1990; Mattingly, 1996; Ganesan, 2003).

In addition swirling flows are used to improve and control the mixing process between fuel and air streams and enhance heat release rate (Beer and Chigier, 1972; Gupta et al., 1984).

\subsection{Geometry}

It is shown in the literature (Lefebvre, 1983) that curved-vane swirlers produce a larger recirculation region and a higher recirculated mass with lower pressure loss. Furthermore, strength of shear layer zones and turbulence intensities are augmented by changing flat vane to curved vanes (Lefebvre, 1983). Therefore curved vane swirlers are selected in this research to show its effect on the flow pattern within the combustor.

The geometrical details of the model swirler, which was carefully machined from mild steal, are given in Figure 1 . The swirler has eight curved vanes, equally distributed around the circumference of its plate. The axial depth of inlet passage is $20 \mathrm{~mm}$. Three different vane angles of $40^{\circ}, 50^{\circ}$ and $60^{\circ}$ were used for this study.

\subsection{Swirler number}

The degree of swirl for a swirling flow is usually characterized by the swirl number, $S$, as was originally proposed by (Chigier and Beer, 1964):

$$
S=\frac{2 G_{\phi}}{R G_{x}}
$$

where $G_{\phi}$ stands for the axial flux of the tangential momentum, $G_{x}$ is the axial flux of the axial momentum, and $R$ is the outer radius of the annulus. These two parameters, $G_{\phi}$ and $G_{x}$ can be expressed as:

$$
\begin{aligned}
G_{\phi} & =\int_{0}^{R} \rho(W r) U 2 \pi r d r \\
G_{x} & =\int_{0}^{R} \rho U^{2} 2 \pi r d r
\end{aligned}
$$

where $U, W, \rho$ are the axial velocity, tangential velocity and density respectively.

Shee et al. (1996) experimentally derived a modified correlation for swirl number that was found to be strongly dependent on Reynolds number (Re) and the vane angle for a radial-type swirl generator. The modified swirl number $S$ correlated with both the Reynolds number and the vane angle. The derived correlation is:

$$
S=C_{1}(\mathrm{Re}) \sigma(\theta)
$$

where $\mathrm{C}_{1}$ is a function of $\mathrm{Re}$ and can be obtained from the following correlation:

$$
\mathrm{C}_{1}=0.28 \times\left[1-\operatorname{sech}\left(0.026 \mathrm{Re}^{0.67}\right)\right]
$$

The values of $\mathrm{C}_{1}$ against $\mathrm{Re}$ is shown in Figure 2. It can be seen that for high Reynolds number, $\mathrm{C}_{1}$ becomes constant and can be taken as 0.28 .

$\sigma$ is the ratio of the mean tangential and radial velocity components at the swirler exit, which has a radius $R_{1}$ as shown in Figure 3. Since $\sigma$ is dependent only on the geometrical dimensions of the guide vane and the vane angle $\theta$, the angle of the guide vane cord line with respect to the radial direction, the value of $\sigma$ can be obtained from the following relations:

$$
\sigma(\theta)=\frac{1}{1-\psi}\left(\frac{\tan \theta}{1+\tan \theta \tan (\pi / z)}\right)
$$

where $\psi=z s / 2 \pi R_{I} \cos \theta$ is a blockage factor that comes from the finite thickness of the guide vanes, $\mathrm{z}$ is the number of guide vanes, and $\mathrm{s}$ is the thickness of the guide vanes. The technical data of the three swirlers used in this study are listed in Table 1.

\section{Test facility}

The water model test facility was used in the present study for isothermal investigation of flow patterns. The test facility was an open circuit arrangement. The main components consisted of a storage tank, pump, flow meters, a control valve, a combustor model and an outlet pipe. The tubular combustor model was the main test section and was placed inside the main water channel test rig as shown in Figure 4. The whole water channel was filled with water in order to reduce distortion and improve visibility. The combustor model used in the water model test facility was geometrically equal to the one used numerical simulation. It was made from 3mm thick Perspex tube with $140 \mathrm{~mm}$ internal diameter and 400 mm length. 
For flow visualization of the flow pattern, coconut milk liquid was introduced as tracer into the test section using syringe pump. Particle Image Velocimetry (PIV) system was used to measure the velocity vector in the combustor model. The system includes: $20 \mathrm{~mJ}, 10 \mathrm{~Hz}$ pulse Nd-YAG laser and 1024x1024 pixels Kodak CCD camera. The CCD ship inside CCD camera is exposed to first frame scattered light of seeding material particles when they exposed to Laser light sheet and full $1 \mathrm{k} \mathrm{x} 1 \mathrm{k}$ pixel image is acquired. The CCD chip is then cleared and exposed to scattered light from the second pulse of the light sheet, and second full $1 \mathrm{k} \mathrm{x} 1 \mathrm{k}$ pixel image is acquired. Both images are then transferred to the FlowMap Processor via digital connector. The minimum time between these two pulses is $1 \mu \mathrm{s}$.

The inlet volume flow rate into the water tunnel was $200 \mathrm{lit} / \mathrm{min}$ which is equivalent to $3.3 \mathrm{~kg} / \mathrm{sec}$. The water mass flow was kept constant for all the swirlers.

\section{Numerical simulation}

The isothermal flow inside the combustor was simulated using FLUENT 6.3 CFD codes. For the prediction of the isothermal flow fields within the combustion chambers, FLUENT solves the equations for conservation of mass and momentum in their time averaged form.

\subsection{Geometry specification and grid set-up}

The flow through eight vanes radial swirlers was divided into 8 separated volumes; each volume was simulated using hexahedral cooper approach Figure 5.a. The physical domain was decomposed to several volumes to facilitate meshing with cooper hexahedral structured grid. The geometry meshing was done to have a variable density distribution by mean of small mesh size was incorporated in high gradient zone and bigger size in low gradient zone. The grid set-up of the present work is shown in Figure 5.

\subsection{Turbulence modeling}

As mentioned above, FLUENT solves the equations for conservation of mass and momentum in their time averaged form for the prediction of isothermal flow fields. For the process of Reynolds decomposition and time averaging results in unknown correlation of the fluctuating velocity components, a turbulence model is required for equations closure purpose. In the present simulation, k- $\varepsilon$ turbulence model with the default setting were used. Turbulence is represented by the standard k- $\varepsilon$ model, which provides an optimal choice and economy for many turbulent flow (Kim, 1989).

Menzies (2005) had studied the behavior of five k- $\varepsilon$ variants in modeling the isothermal flow inside a gas turbine combustor and compared the results with the experimental data of Da Palma (1988) for the velocity and turbulence fields. The studied models were the standard, the RNG, the realizable, the Durbin modified, and the nonlinear k- $\varepsilon$ models. The results showed that the standard and the Durbin k- $\varepsilon$ models gave the best agreement with the experimental data. This supported the finding of Jiang and Shen (1994) and Durst and Wennerberg (1991) where good agreement between k- $\varepsilon$ model predictions and experimental result were reported.

\subsection{Boundary conditions}

The appropriate choice of boundary conditions is essential and is a critical part in modeling a flow accurately. Typical boundary conditions for FLUENT simulation were the inlet, the wall and the outlet boundaries. At the inlet of the computational region, the inlet boundary condition is defined as mass flow inlet while the exit boundary is defined as pressure outlet (gauge pressure at model outlet is 0.0 ). Some assumptions about boundary conditions that were not directly measured had to be made as follows:

- Velocity components and turbulence quantities at the inlet were constant

- Turbulence at inlet is calculated from the following equations (Versteeg and Malalasekera, 1995):

$$
\begin{gathered}
k_{\text {inlet }}=0.002\left(u^{2}\right)_{\text {inlet }} \\
\varepsilon=\frac{k_{\text {inlet }}^{1.5}}{0.3 D}
\end{gathered}
$$

\section{Results and discussion}

In order to investigate the effect of vane angle on the flow pattern within the combustor model, the prediction results using Fluent code for $40^{\circ}, 50^{\circ}$ and $60^{\circ}$ vane swirler are presented and discussed in the following section.

\subsection{Numerical results}

The swirl number was numerically computed for the three radial swirlers using the integration listed in Equations 2 and 3 on the swirler exit plane. The different values of swirl number are listed in Table 1. It can be observed that the calculated swirl number has a good agreement with that obtained from experimental correlation 5. 
Figures 6, 7 and 8 show velocity contours within the recirculation zone for the various vane swirlers. These contours are obtained by plotting the axial velocities which ranges from maximum negative value to zero within the recirculation zone. The flow downstream of $40^{\circ}$ swirler shows maximum reverse velocity of $0.63 \mathrm{~m} / \mathrm{s}$ as seen from Figure 6 which shows the formation of recirculation zone. Maximum reverse velocity magnitude of 1.02 and $1.04 \mathrm{~m} / \mathrm{s}$ are found for $50^{\circ}$ and $60^{\circ}$ swirlers respectively as seen from Figure 7 and Figure 8 . The region with reverse velocity is termed as central recirculation zone (CRZ), which is mainly responsible for flame stabilization. As it can be seen from Figure 6 the recirculation zone has smaller size and shorter length with a width of $1.53 \mathrm{D}_{1}$ and length $4.85 \mathrm{D}_{1}$. This recirculation zone is critical as far the residence time for the reactant species and the heat transfer rate are concerned. The above parameters, in turn, depend on the volume and surface area of the recirculation zone. Hence, it will be useful to investigate the effect of the vane angle on the geometry namely the length, width, surface area and the volume of the recirculation zone. For the $50^{\circ}$ vane swirler, it is seen from Figure 7 that the length and width of the recirculation zone has increased to $1.86 \mathrm{D}_{1}$ and $5.6 \mathrm{D}_{1}$ respectively compared to $40^{\circ}$ swirler, and the longest length of $9.6 \mathrm{D}_{1}$ and widest width of $1.93 \mathrm{D}_{1}$ are obtained for the $60^{\circ}$ vane angle swirler. Figures 6,7 and 8 also show that the size of the corner zone circulation decreases with the increase of the swirl number.

Total Pressure loss is a dimensionless number and is defined as:

$$
\text { Pressure Loss } \%=\frac{P_{o 2}-P_{o 1}}{P_{o 1}}
$$

where $P_{o l}$ is the inlet stagnation pressure, measured at the inlet plenum upstream of the swirler and $P_{o 2}$ is the exit stagnation pressure, obtained in the combustor exit section. The variation of pressure loss with the swirl number is shown in Figure 9. It is seen that with increase in vane angle, pressure loss also increases. Furthermore, Figure 9 shows that there is a steep increase in pressure when the vane angle is increased from $50^{\circ}$ to $60^{\circ}$. For efficient design of combustion chamber the pressure loss should be as minimum as possible, however, it should have more recirculated gases in the recirculation zone. So a compromise is required between the recirculation zone formed and the total pressure loss across the swirler. Taking these factors into account it is found that the total pressure loss across $60^{\circ}$ swirler is nearly 1.7 times higher than that for $50^{\circ}$ swirler as well the recirculation zone size of $45^{\circ}$ is quite sufficient.

Briefly, the volume of recirculation zone formed for $50^{\circ}$ and $60^{\circ}$ swirlers are close with pressure loss for $60^{\circ}$ swirler is approximately twice that of the $50^{\circ}$ swirler. Hence it is concluded that the $50^{\circ}$ vane swirler produces good recirculation zone with reasonable pressure drop, which may aid better combustion.

\subsection{PIV results}

Figures 10, 11 and 12 illustrate the streamlines profiles for $40^{\circ}, 50^{\circ}$ and $60^{\circ}$ vane angle swirlers. The scale for PIV image is 150 pixel per $100 \mathrm{~mm}$ according with the datum sets at the value of zero. These figures show that, there are three recirculation zone created inside the combustor model. One recirculation was formed in the corner and two were formed in combustor central zone. The poor agreement between the experimental and numerical results owes to the following reasons:

- High swirl flow which makes residency time of the seeding particle in measuring stream-wise plane for two successive frames unfeasible.

- The curved surfaces such used in the circular combustor model reflect a fraction of the laser light sheet which affects the quality of the image hence the accuracy of measurement.

\section{Conclusion}

The study of the flow pattern inside a gas turbine combustor model using numerical simulation and experimental approach has been achieved. Numerical simulation was done using Fluent 6.3 and based on standard k-epsilon turbulence model while experimental work was accomplished using PIV system.

The three radial swirlers employed in this research show a significant effect on the flow pattern within the combustor model. The $40^{\circ}$ vane angle swirler produced a small volume of recirculation zone while $50^{\circ}$ and $60^{\circ}$ vane angle swirler produced larger recirculation zone size. From the parametric study carried out with varying angle of vanes, it is found that $50^{\circ}$ swirler is the best for producing appropriate recirculation zone with reasonable pressure drop.

It can be concluded also that with the increase of the swirler vane angle, the corner circulation or dead zone size decreased as the tangential to axial momentum ratio increased. This dead zone has a negative impact on the combustion process and the homogeneity of the wall temperature as well.

Finally, it is recommended for high swirling flow to use 3D PIV system instead of 2D PIV used in this paper.

\section{References}

Beer, J.M. \& Chigier, N.A. (1972). Combustion Aerodynamics. Applied Science Publisher, London 
Chigier, N. A., \& Beer, J. M. (1964). Velocity and Static-Pressure Distributions in Swirling Air Jets Issuing from Annular and Divergent Nozzles. Journal Basic Eng., 788-796.

Da Palma, J. M. L. M. (1988). Mixing in Non-Reacting Gas Turbine Combustor Flows. PhD Thesis, University of London, UK.

Durst, F. \& Wennerberg D. (1991). Numerical Aspects of Calculation of Confined Swirling Flows with Internal Recirculation. Int. J. for Numerical methods in Fluids, Vol. 12, 203-224.

FLUENT 6.3 User's Guide, Fluent Inc. 2006.

Ganesan, V. (2003). Gas Turbines. Tata McGraw-Hill, New Delhi.

Gupta, A.K, \& Lilley, D.G., \& Syred, N. (1984). Swirl Flows. Energy and Engineering Science Series, Abacus Press, England.

Jack D. Mattingly, (1996). Elements of Gas Turbine Propulsion. McGraw-Hill International Edition, Singapore.

Jiang, T. L. \& Shen, C. H. (1994). Numerical Predictions of the Bifurcation of Confined Swirling Flows. Int. J. for Numerical methods in Fluids, Volume 19, 961-979.

Kim, Y.M. and Chung, T.J. (1989). Finite-Element Analysis of Turbulent Diffusion Flames. AIAA Journal, Vol. 27 , No. 3, pp. 330-339.

Lefebvre, A. H. (1983). Gas Turbine Combustion. Hemisphere Publishing Corporation, first edition.

Mellor, M. (1990). Design of Modern gas Turbine Combustors. Academic Press.

Menzies, K. R. (2005). An Evaluation of Turbulence Models for The Isothermal Flow in A Gas Turbine Combustion System. 6th International Symposium on Engineering Turbulence Modeling and Experiments, Sardinia, Italy.

Shee, H. J. \& Chen W. J.\& Jeng, S.Y. \& Huang, T. L. (1996). Correlation of swirl number for a radial-type swirl generator. Experimental Thermal and Fluid Science, 12, 444-451.

Versteeg, H. K., \& Malalasekera, W. (1995). An Introduction to Computational Fluid Dynamics, the Finite Volume Method. Longman Group Ltd.

Table 1. Technical data of the swirlers

\begin{tabular}{|c|c|c|c|}
\hline Swirler & A & $\mathrm{B}$ & $\mathrm{C}$ \\
\hline Vane angle, deg & 40 & 50 & 60 \\
\hline Vane depth, mm & \multicolumn{3}{|c|}{20} \\
\hline No. of vanes & \multicolumn{3}{|c|}{8} \\
\hline Vane thickness, mm & \multicolumn{3}{|c|}{6} \\
\hline Outlet radius $\mathrm{R}_{1}, \mathrm{~mm}$ & \multicolumn{3}{|c|}{20} \\
\hline $\mathrm{C}_{1}$ based $\mathrm{Re}_{\mathrm{in}}=21900$ & \multicolumn{3}{|c|}{0.28} \\
\hline $\mathrm{S}$ based on Equation & 0.35 & 0.54 & 1.13 \\
\hline Calculated from CFD & 0.45 & 0.587 & 0.97 \\
\hline
\end{tabular}



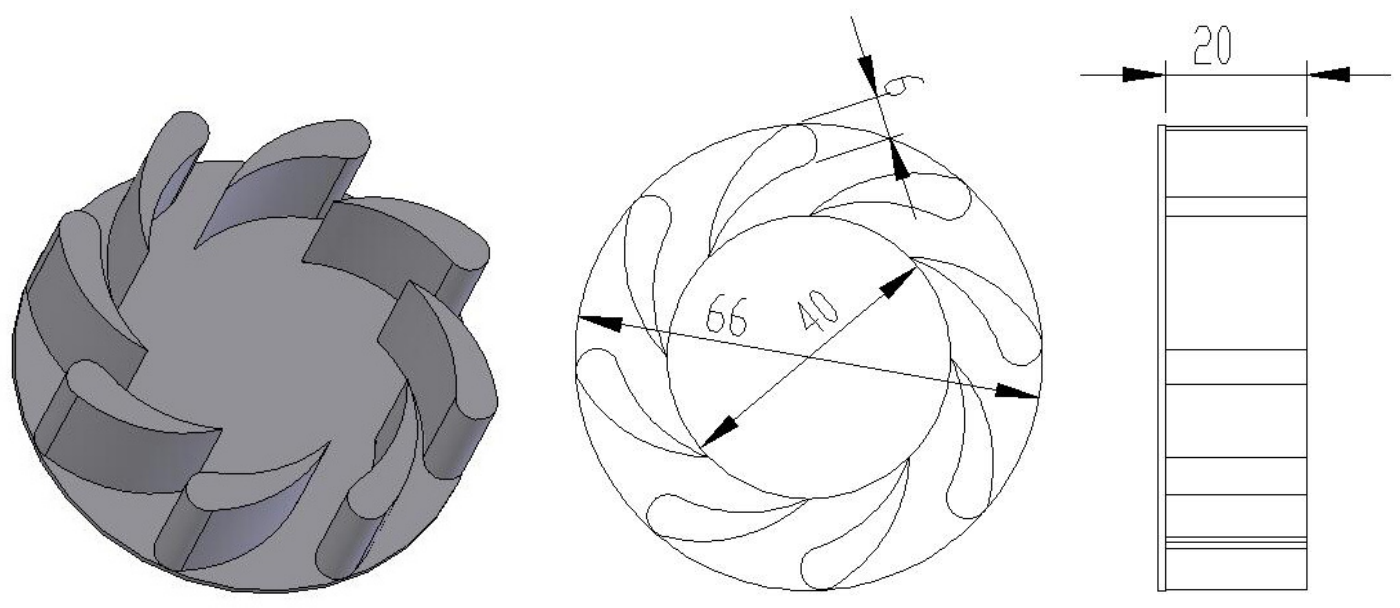

Figure 1. Geometrical details of the model swirler (all dimensions in $\mathrm{mm}$ )

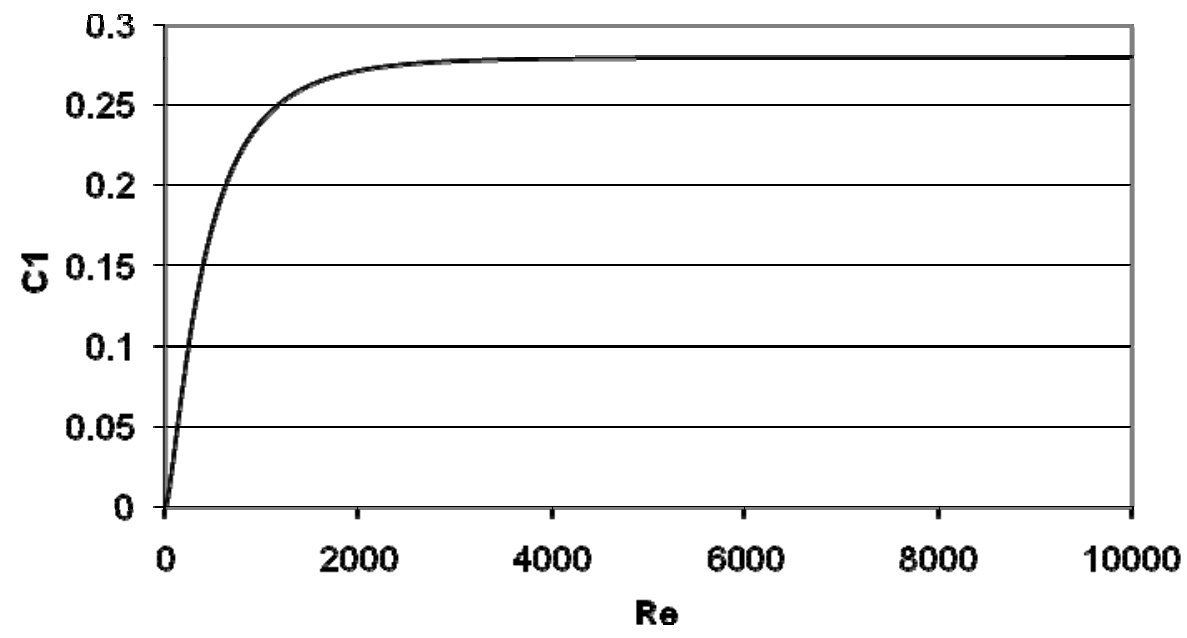

Figure 2. Correlation for the constant $\mathrm{C}_{1}$ Reynolds number.

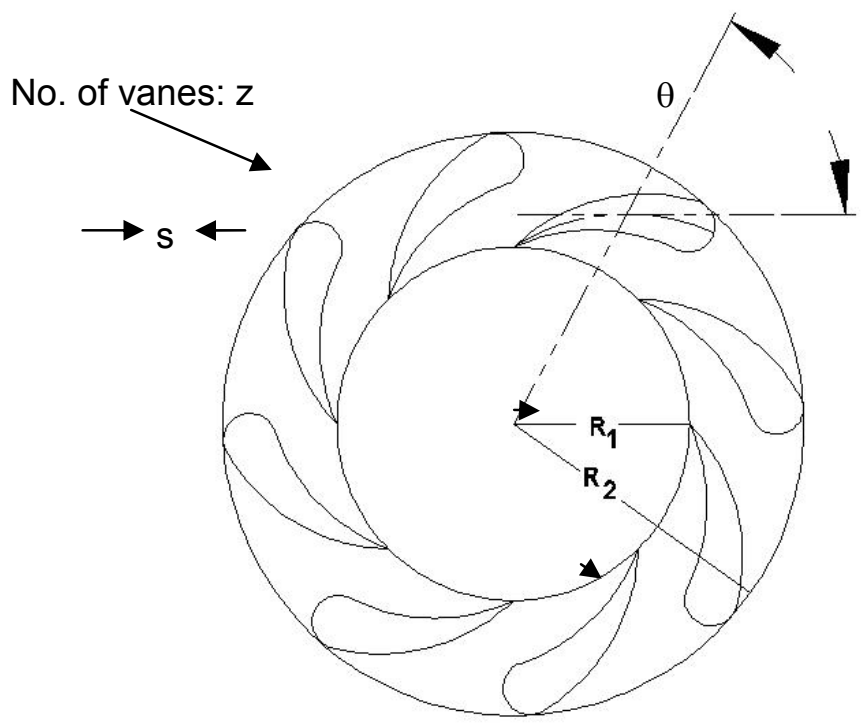

Figure 3. Guide vane cascade in the radial swirler 


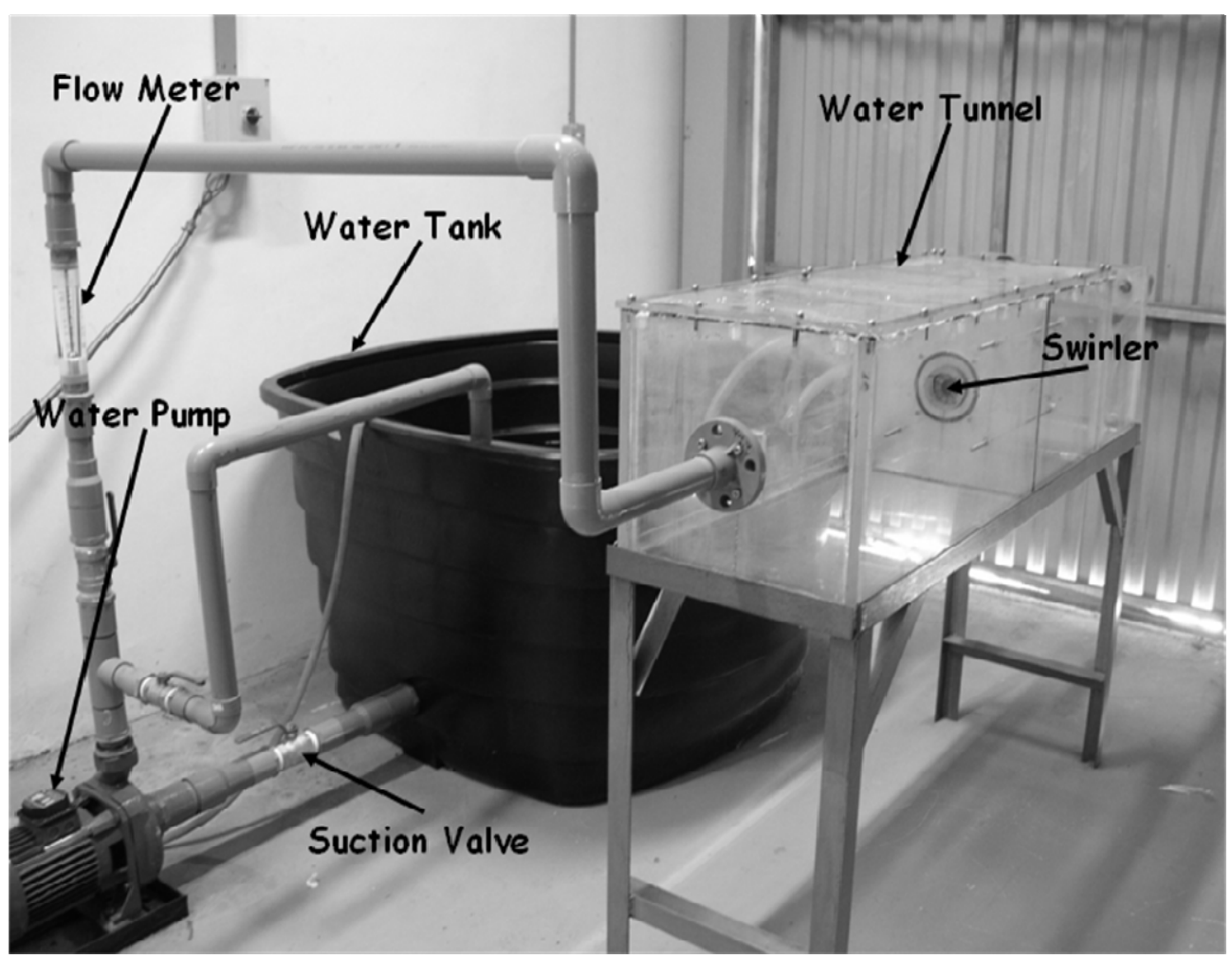

Figure 4. Water channel test rig

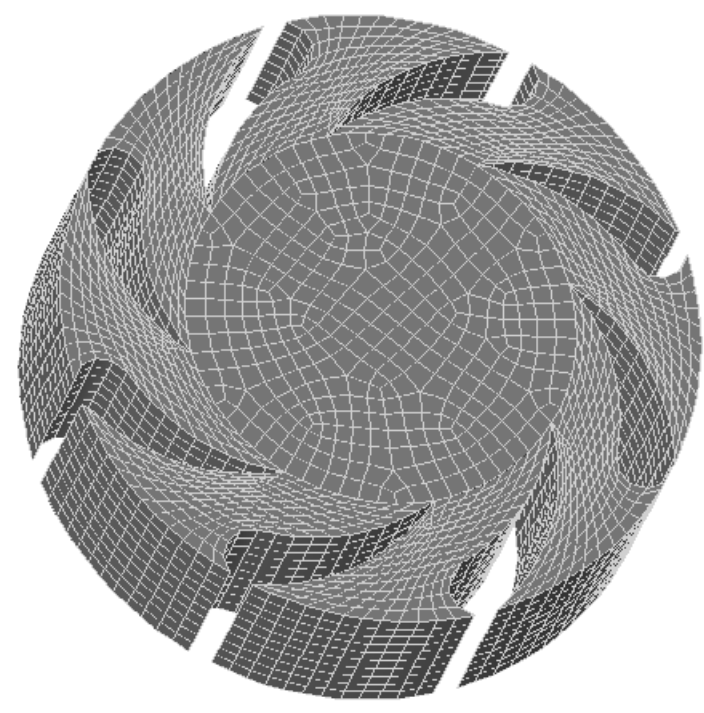

(a) 


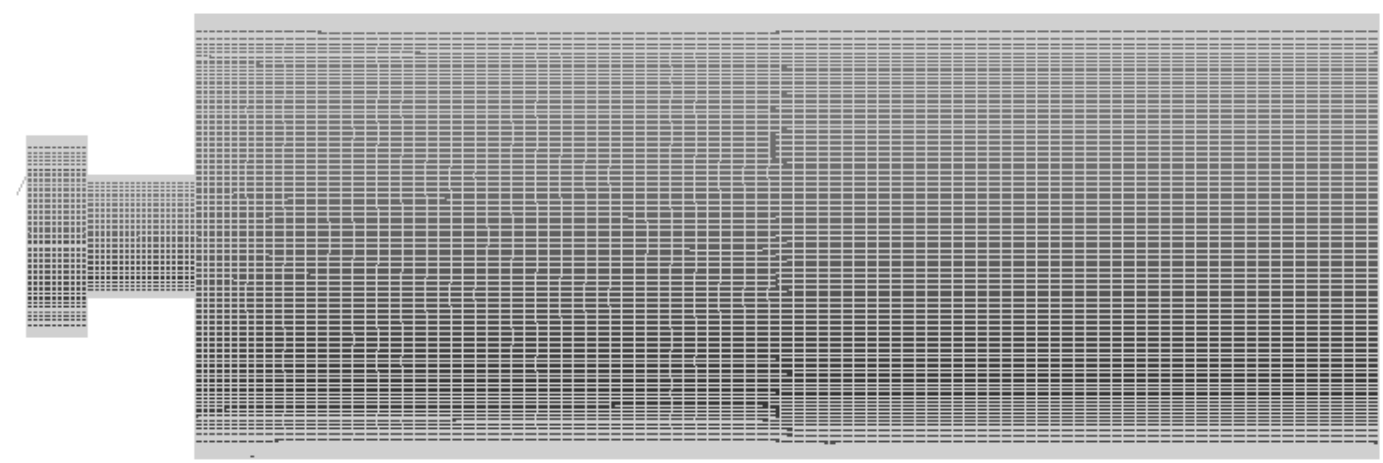

(b)

Figure 5. Grid set-up (a) Swirl passage volume mesh (b) Combustor model mesh

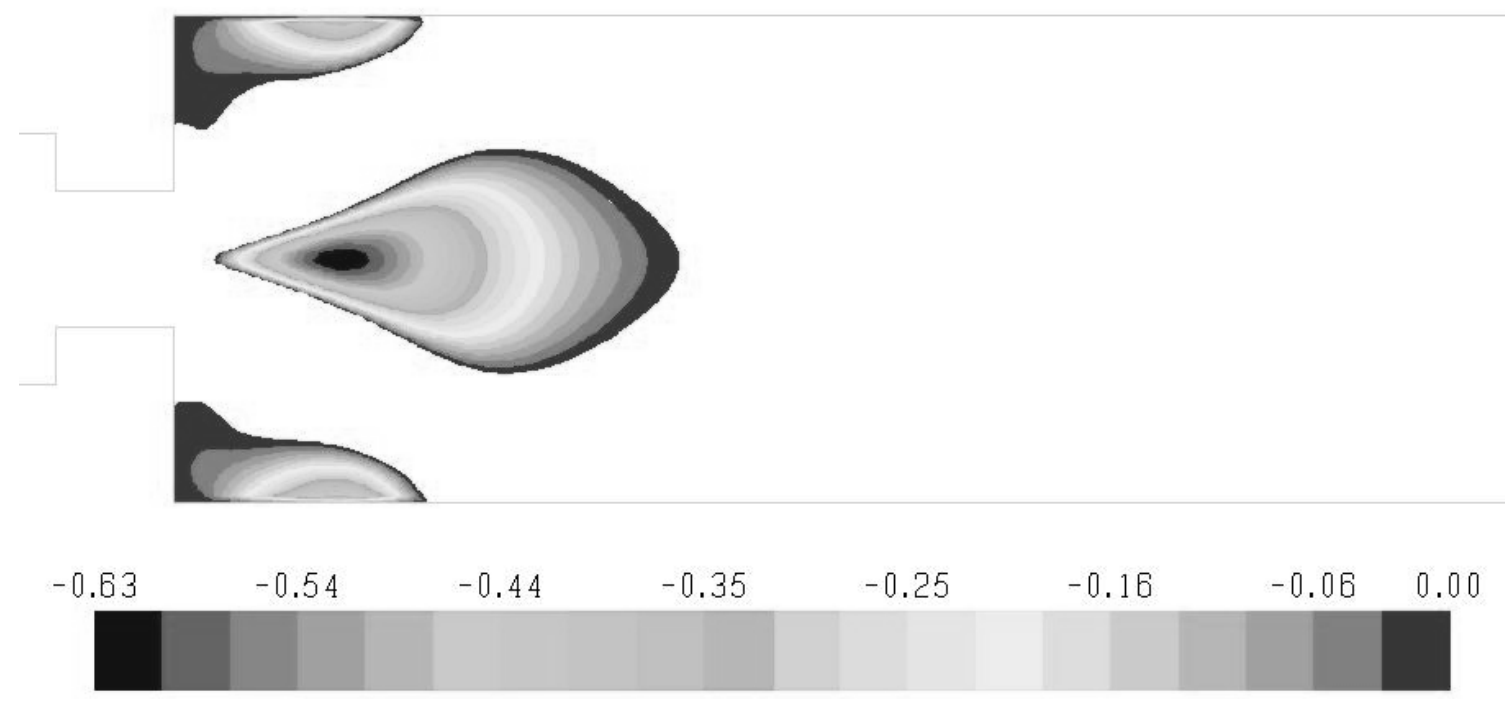

Figure 6. Velocity contour within recirculation zone for $40^{\circ}$ swirler

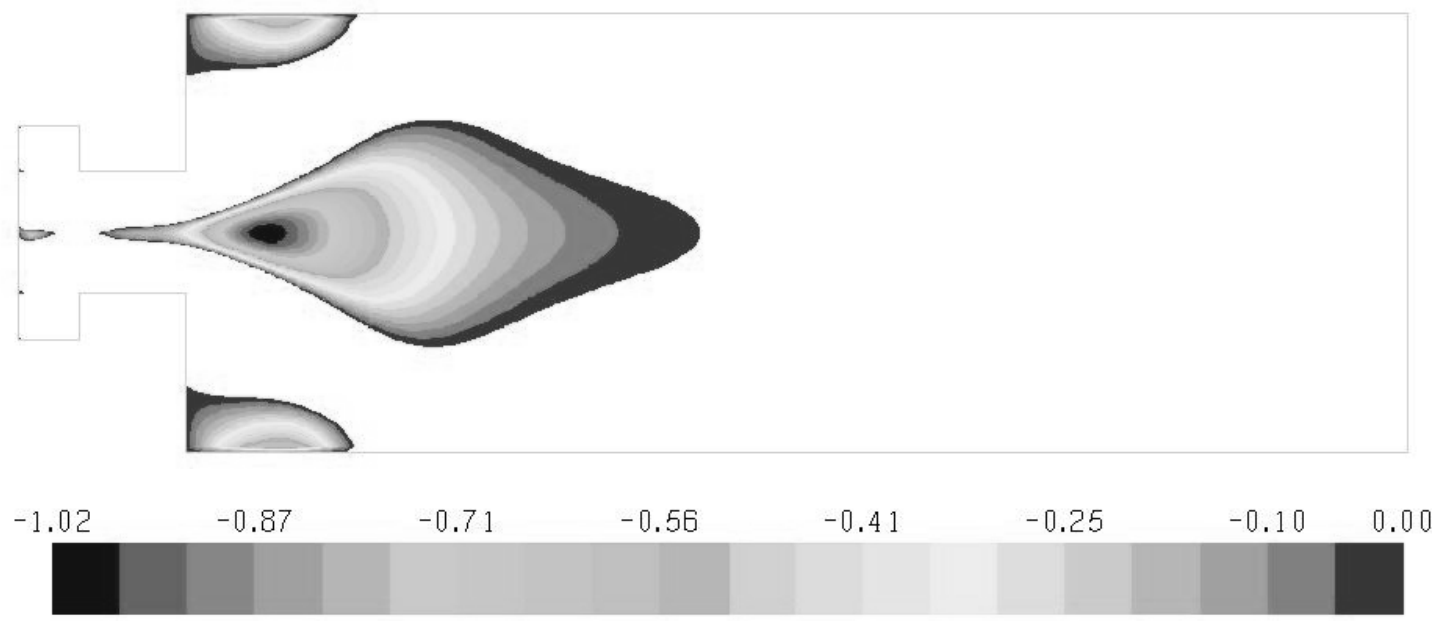

Figure 7. Velocity contour within recirculation zone for $50^{\circ}$ swirler 


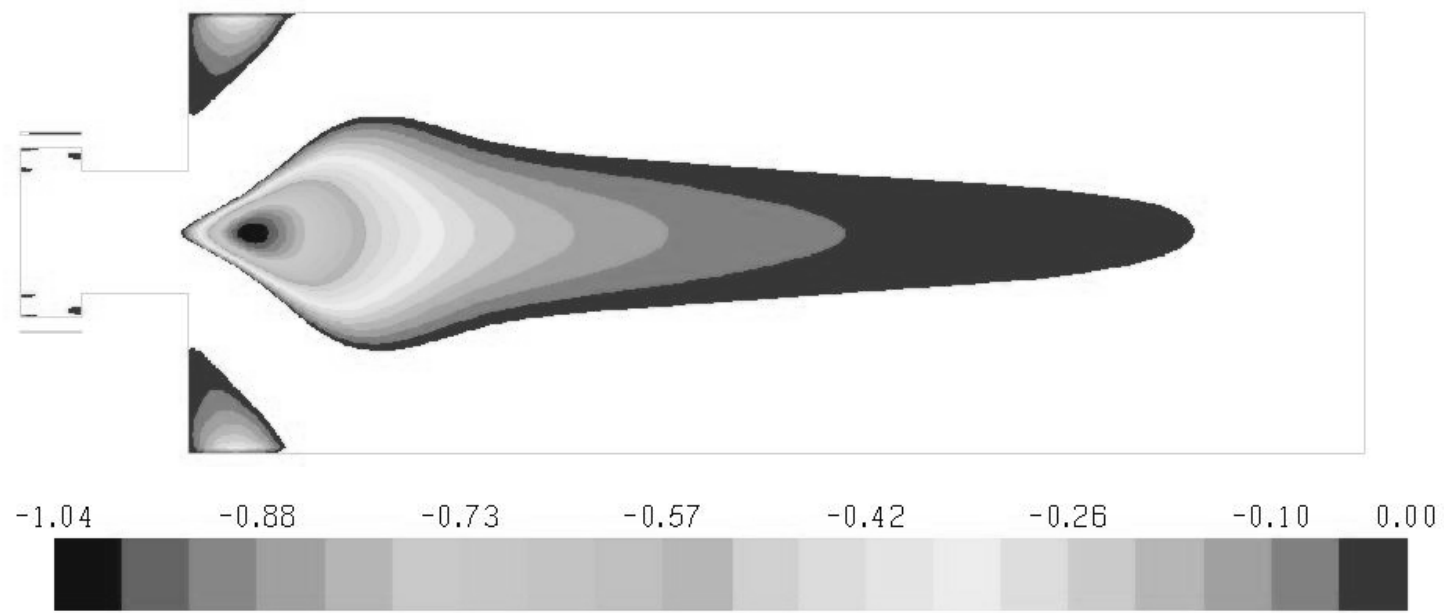

Figure 8. Velocity contour within recirculation zone for $60^{\circ}$ swirler

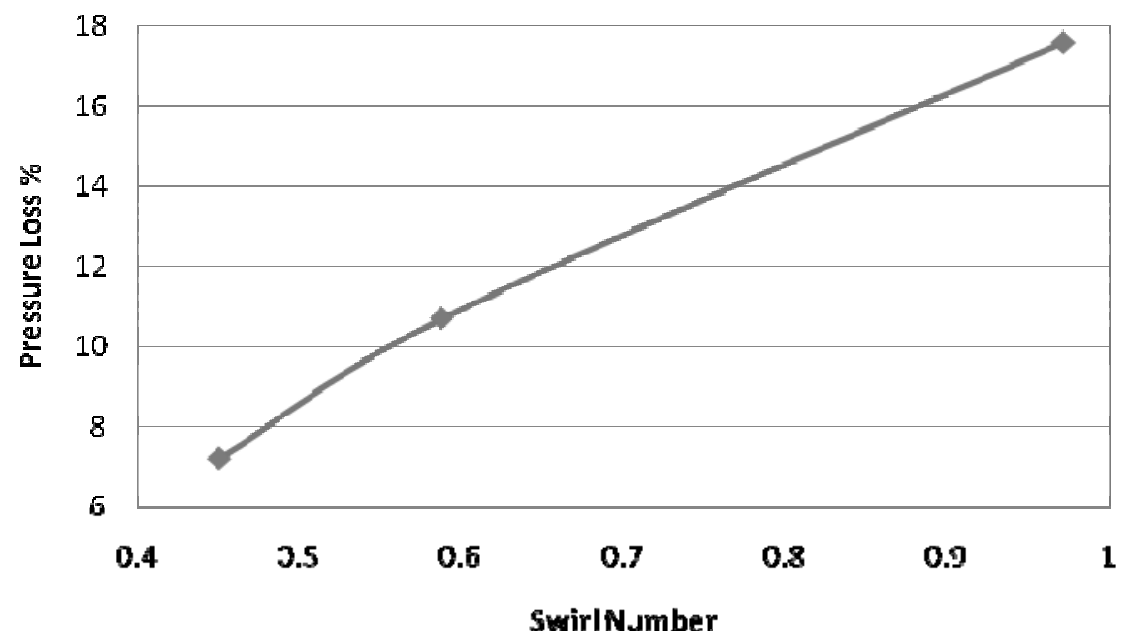

Figure 9. Total pressure loss $\%$ of various swirlers.

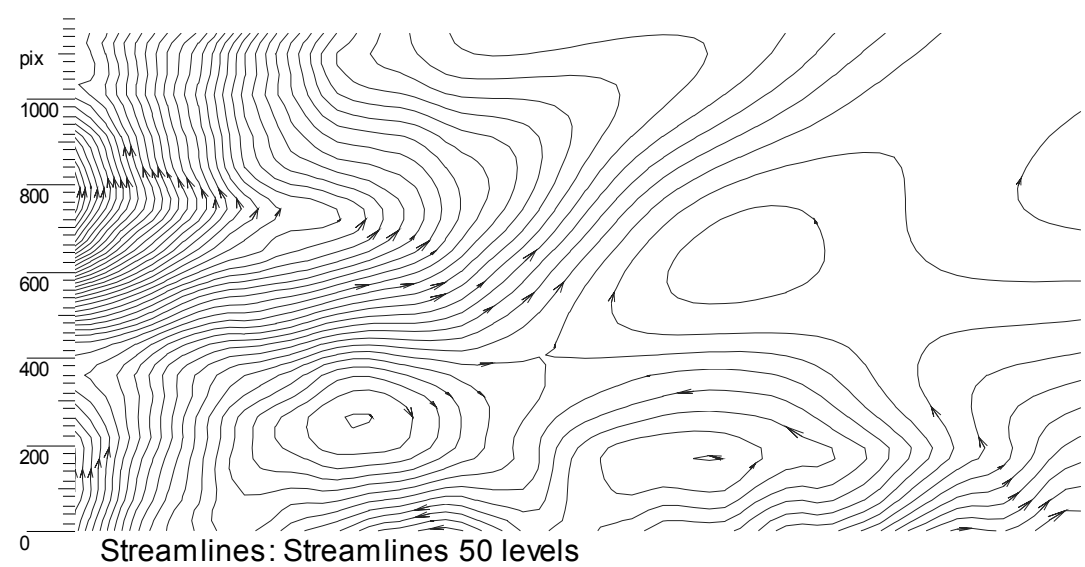

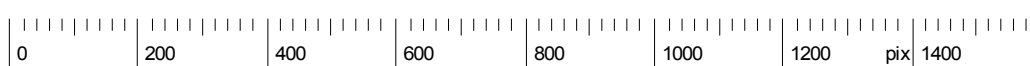

Figure 10. Streamlines of $40^{\circ}$ vane angle swirler in the mid plane 


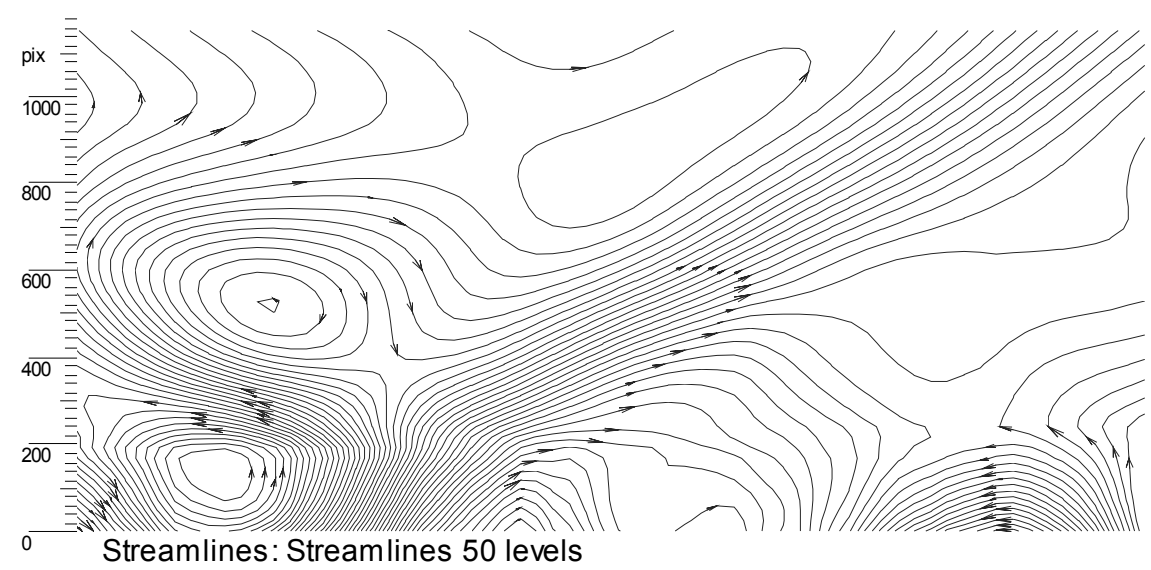

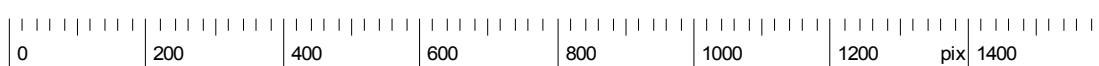

Figure 11. Streamlines of $50^{\circ}$ vane angle swirler in the mid plane

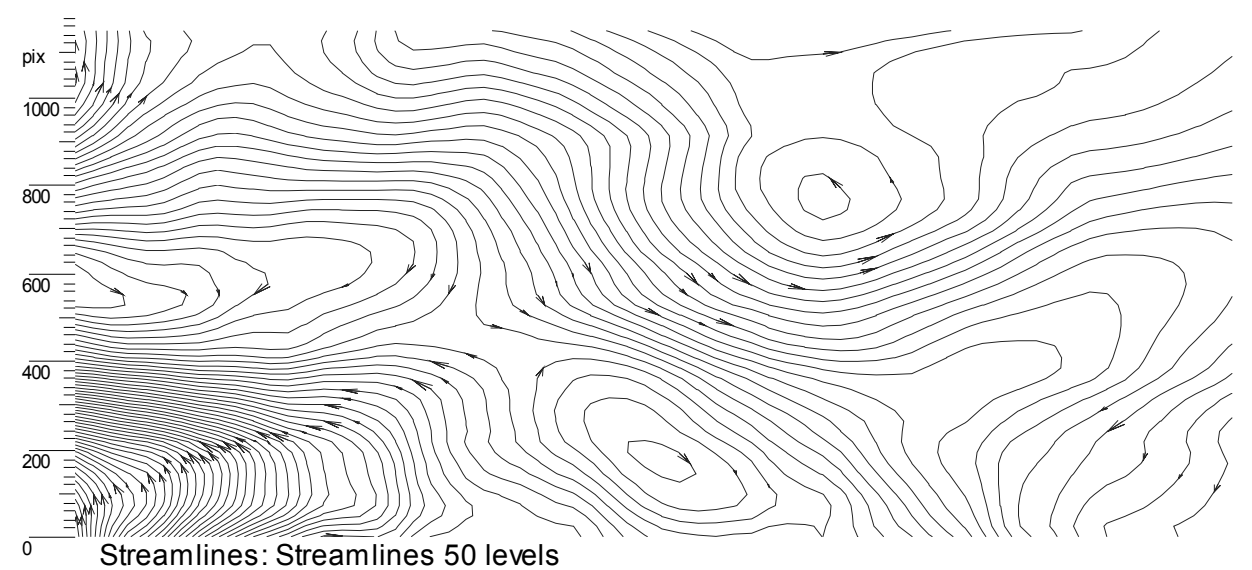

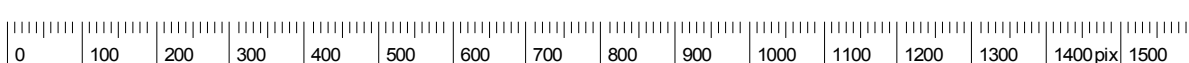

Figure 12 . Streamlines of $60^{\circ}$ vane angle swirler in the mid plane 